\title{
The Internet of Total Corporate Communications, Quaternary Corporate Communications and The Corporate Marketing Internet Revolution.
}

\author{
John M.T. Balmer * and Dorothy A. Yen* \\ *The Marketing and Corporate Brand Research Group, Brunel Business School, Brunel University \\ London, UK. \\ August 16th 10:30
}

\begin{abstract}
The advent of what we call, "The Corporate Marketing Internet Revolution" necessitates a radical rethinking of marketing practice and scholarship. As such, mindful of the importance of the internet, and in particular, the Internet of Things (IoT) phenomena this article formally introduces and elucidates the Internet of Total Corporate Communications (IOTCC) notion. Moreover, it particularises the nature and importance of quaternary (fourth-order) total corporate communications. To date, the total corporate communications effects of the Corporate Internet Marketing Revolution has not been accorded importance in the extant literature. As such, this article seeks to address this omission.
\end{abstract}




\section{Introduction and Purpose}

To us, what we call, "The Corporate Marketing Internet Revolution” is beginning to be recognised and taken account. The aforementioned-a product of the Fourth Industrial Revolution-is, arguably, one of the most significant corporate marketing developments of the new millennia and is a phenomenon of considerable import.

Mindful of the importance of the internet, and in particular, the Internet of Things (IOT) phenomena on this aforementioned this article formally introduces and elucidates the Internet of Total Corporate Communications (IoTCC) notion. Moreover, it particularises the nature and importance of quaternary (fourth-order) total corporate communications. To date, the total corporate communications effects of the Corporate Internet Marketing Revolution has not been accorded importance in the extant. As such, this article seeks to address this omission.

Our article proceeds by providing a contextual overview by discussing the Corporate Marketing Internet Revolution; detailing the nature of the Internet of Things; explaining the total corporate communications conceptualisation; formally introducing the Internet of Total Corporate Communications notion; specifying Quaternary Total Corporate Communications; outlining the impacts of quaternary total corporate communications; discussing the dark side of IOT and the Internet of Total Corporate Communications: marketing management implications and finally, providing some final reflections.

\section{Context: The Corporate Marketing Internet Revolution}

It is an incontrovertible fact that we are now in the midst of new, powerful and prevalent marketing revolution with the opening-up of the digital and technological cosmos of which the materialisation of the Internet of things is emblematic. We call this revolution, “The Corporate Marketing Internet Revolution”.

By means of context we sit on the edge of a far larger tumult of which the aforementioned, is a consequence of, as well as an integral part of, the Fourth Industrial Revolution (Schwab 2015). The stupefying rise and ubiquity of the internet has resulted in a revolution of a quite different order: one that is s qualifiedly different in scale, scope and significance from its antecedents. 
Unquestionably, this Revolution -as with formal transformations-has the potential to be of considerable consequence: some of them as yet unforeseen. What is clear is that this will transform the marketing discipline in both scholarly and instrumental terms.

Why is this so? This is because this revolution will cause marketing scholars and managers to reappraise the interfaces between organisations, society, peoples and, in particular, the relationships between organisations and their customers and key stakeholders.

Of course, many organisations have identified market opportunities in all this. For instance, the internet and moreover the internet of things have led to the establishing of new companies and the broadening of the scope of others. As noted by Roberts (2004, p. 13) the starting point for a business opportunity is to identify a market insufficiency: an unmet need.

Tellingly, corporations are beginning to invest heavily in the internet of things: Google acquired Nest for $\$ 3.2$ billion (a thermostat maker) and $\$ 550$ million for Dropcam - a manufacturer of security cameras for the home (The Economist, 2016a).

This raises the question as to what is different about this technological revolution? Whereas the initial three industrial revolutions transformed the production, delivery and consumption of products and services, the fourth industrial revolution goes further by altering the analysing, thinking, recommending and moreover controlling of the aforementioned. This is the basic premise of this transformation but, as we will detail, there can be a dark side to the above which can result in a loss of customer and stakeholder sovereignty (Balmer and Greyser, 2006); greater organisational and governmental implementation and, in short, a move away from a marketing to corporate and governmental - led mind-set (analogous to the classic product-led approach outlined in marketing primers).

So what is special about this new transformation? As noted by Schwab (2015), whereas the earlier industrial revolutions were characterised by:

1. mechanical production ( $18^{\text {th }}$ Century),

2. division of labour, electricity, mass production ( $19^{\text {th }}$ century)

3. electronics, IT and automated production (late $20^{\text {th }}$ century)

However, as Schwab (2015) deliberates, the fourth industrial revolution has the prospect of connecting billions of people via mobile devices, with extraordinary 
processing capabilities, storage capacity, and infinite knowledge access. Moreover, the above will augmented through technology breakthroughs vis-a-vis the Internet of Things (IOT) artificial intelligence, biotechnology, energy storage, materials science, nanotechnology, quantum computing, robotics, 3-D printing etc. Moreover, it will materially affect our way of life in terms of how we live, work, and interact with each other.

Earlier on we referred to a new marketing revolution. Whilst the history of marketing thought is varied (Balmer and Greyser, 2006). Various marketing "revolutions" have not vitiated the saliency of early transformations but, rather, broaden the territory (Balmer, 2011). For the sake of both expediency and simplicity, it can be averred the 4 marketing revolutions are as follows:

- the first marketing revolution was the establishment of a distinct philosophy of marketing. Based largely on products and product brands, this philosophy focussed on mutually beneficial company-customer exchanges.

- the second marketing revolution adapted this philosophy to services.

- more recently, the third revolution broadened this philosophy to organisations, their corporate identities and corporate brands. Notably, the focus was not only on customers but on stakeholders (company-stakeholder exchanges).

- the forth marketing revolution recognises that a reformation of marketing thought and philosophy is urgently required with the advent of the ubiquity and importance of the digital age and the spectacular ascendancy (and in certain regards hegemony) of the internet. Clearly, the internet of things is one, prominent, manifestation of the aforementioned. See Fig. 1 for a graphic representation of the above. 
Mutually beneficial company-customer exhcange relationships based on products/product brands

Mutually beneficial company-customer exchange relationships based on services/services brands

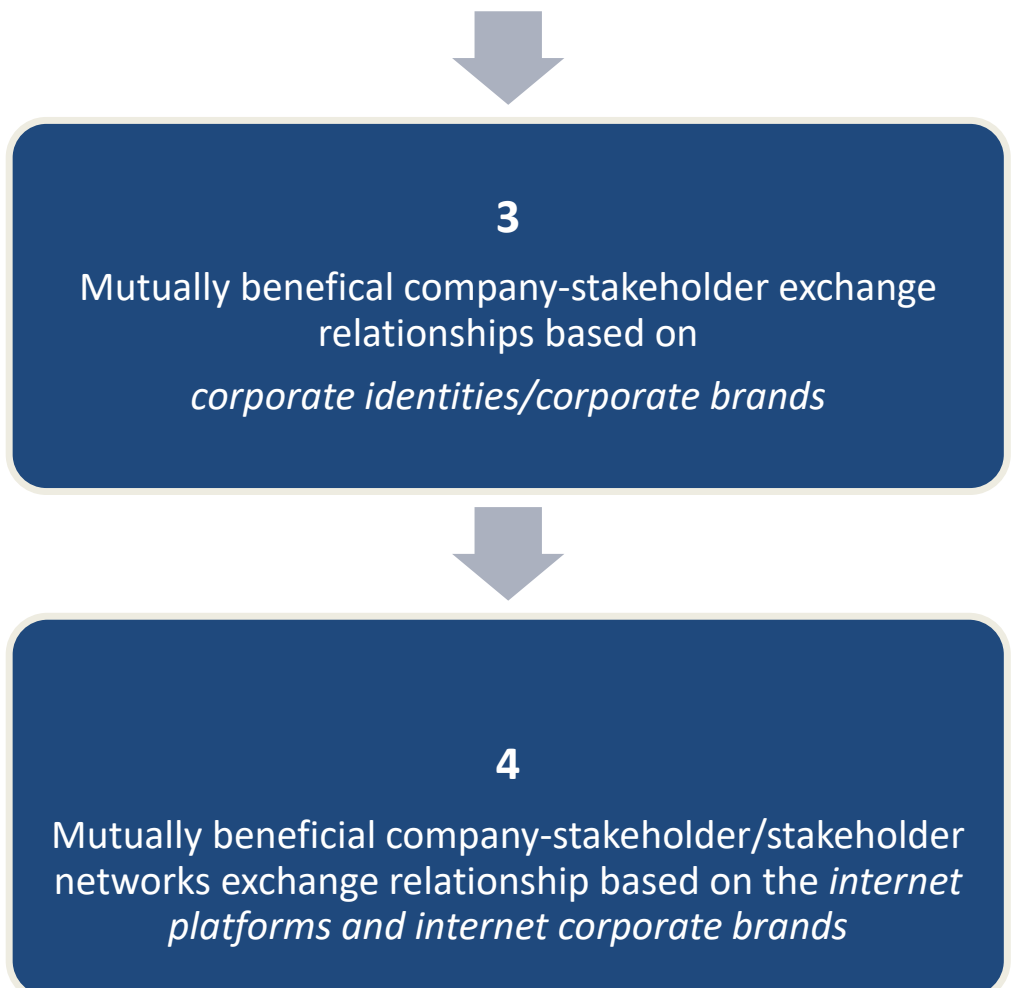

\section{The Internet of Things}

The Internet of Things (IOT) was considered a novel paradigm back in 2010 (Atzori, Lera, and Morabito, 2010).

What is the internet of things? In essence, IOT refers to a computing concept where every day physical objects can be connected to the Internet (and to each other) 
via tags, chips, or via a specific digital technology such as RFID (radio frequency identification).

As recently reported in the Economist (2016), for some considerable time now, forecasters have prophesied that the addition of internet capability to products, especially home and "white goods". As such, the IOT empowers consumers to control white goods and other items and services from afar. Exemplars include fridge sensors which identify rotten food; cameras which can monitor activities in homes from afar; and controls which allow for remote control of central heating and so.

In our estimation, the IOT not only has the potential to empower customers but also alters modifies in new, and in sometimes unexpected ways, company-customer relationships.

However, the prosaic utility of IOT apropos white goods etc. is, in fact, somewhat narrowly conceived. This is because rather than being limited to computers, tablets, smartphones, white goods, the IOT realm encompasses any device that can be connected and communicate in an intelligent fashion.

Moreover, as observed by Atzori et al. (2010) there are five application domains which are, at present, germane for IOT. These include transportation and logistics, healthcare, smart-environments, personal and social.

Other scholars have averred how the IoT is essential for organisational innovation, adaptation and success. This is especially for firms with high amounts of connectivity, network and data (Jones, Suoranta, \& Rowley, 2013; Yadav, Prabhu, \& Chandy, 2007; Yu, Nguyen, \& Chen, 2015). As noted by Chui, Löffler and Roberts, (2010) apropos IOT, Japanese organisations are now utilising billboards to scrutinising would-be consumers in terms of their profiles and then go ahead to target bespoke advertisements on the billboards.

Importantly, the internet of things also operates in business to business (B2B) domains. For example, B2B manufacturers improve both efficiencies and economies of scale via the implantation of sensors in factory equipment, for example.

What does the IOT mean in communications terms? For us, this representing an exciting, albeit challenging, development. Why? This is because the loT thus has the potential to become one big information universe. By means of context it should be noted that the IOT enables data generated autonomously on everyday human behaviour. 
On the positive side (there is a dark side) the IOT may foster efficiency, convenience and a better quality of life for consumers. It also, of course, enables companies-and also third parties, to be privy to consumer behaviour, preferences and influences. Such is the potential ubiquity of iOT that information of this kind is collected from devices and among individuals connecting via such devices. As such, communication and information feedback and encompasses communication between devices and consumers/others; communication between devices, as well as strings of communications. For scholars such as Tan and Wang (2010), this represents a new era in computing. Significantly, extant scholarship on loT reveals a preponderance of contributions deriving from information system disciplines.

In terms of marketing scholarship vis-à-vis IOT, this lags behind the information technology field. Moreover, our initial examination of the territory suggests that the corporate communications effects of the IOT remains in its infancy and at best adolescence.

Before formally introducing and explication the internet of total corporate communications notions, by means of background, a short precis of the total corporate communications conceptualisation will be detailed.

\section{Total Corporate Communications}

By means of context, a short resume of the precepts of total corporate communications are likely to be efficacious.

The total corporate communications notion has an explicit stakeholder orientation and takes account that everything an organisation says, makes and doesalong with third party commentary-communicates (Balmer and Gray 1999).

Moreover, the aforementioned state that represents a nexus linking a company's corporate identity (a firm's distinguishing and defining traits) and the corporate images and reputations held of an entity by stakeholders. These are important since they provide the foundations of stakeholders identifications and behaviours which can meaningfully support the company's mission and purpose as evinced in its corporate identity (or not).

Total corporate communications are differentiated from traditional one-way communications models which emphasise "controlled communications". As detailed by Balmer and Gray (1999) Total corporate communications encompasses: 
1 primary communications: the total corporate communications impacts of corporate activities and behaviours, product and service quality, management and employee behaviour etc.;

2 secondary communications: the total corporate communications impacts of controlled corporate communications such as corporate advertising, corporate design, corporate public relations, etc.;

3 tertiary communications the total corporate communications effects of thirdparty/uncontrolled communications.

[Insert Figure 2: The total corporate Communications effect of the internet of things here]

\section{Introducing the Internet of Total Corporate Communications notion}

Given the rise of interest in and importance attached to the loT the formal introduction of IoTCC appears to be timely. Why? This is because this new loT conjoins and advances both the lot and the total corporate communications fields and, therefore, has the potential to afford scholarly and practical insights.

For consumers and other key stakeholders, utilising loT apropos smartwork/smart-home devices, perhaps without realising it, are in effect, engaged in corporate communications. This is because the provider of internet services often collates information about their consumers (and B2B customers too) to betterunderstanding their customers, other key stakeholders and markets. Real time transactions and usage data are automatically collected by app providers linking back to the cloudobased databases of companies and brands. Such customer feedback provides critical marketing information required to better enhance corporate communications.

Moreover, the internet of things is part of a new world of corporate communications where the internet not only responds to requests for information but also recommends companies and their products and services to customers (both business and consumers) and other stakeholders based on their analysis of existing usage profile. For example, many manufacturing firms now analyse their customers' usage and inventory, with automatic devices that send reminds to users and purchasing managers for reordering. Utility firms also deploy "smart" meters that display energy 
usage and the amount that is already consumed with the real time cost of providing it (Chui et al., 2010). Mobile network providers also supply customers with automatic updates of mobile data usage so that consumers are aware if they have exceeded their initial allowance or if extra data purchase is needed. By attending to customers' needs prior to their own recognition, IoT provides businesses with competitive advantages to increase customer satisfaction, confers a positive image.

More generally of course, internet providers, track customers' uses of the internet in order to provide bespoke services and product/service recommendations for them. Moreover, the internet comprises a plethora of organisations providing internet platforms and they determine what and what not to prioritise or exclude for their search engines. Such, of course, is the power of the aforementioned that in certain countries certain internet search engines are proscribed. For examples, several apps such as Facebook, Twitter, etc and search engines such as Google are banned in the People's Republic of China is a case in point.

Over recent decades the world has witnessed the ascendancy of the internet as an information, knowledge, social, marketing, resource. Newly created cloud space is now utilised by people, firms, institutions, products, systems and machines to store and exchange data on a regular basis. In many parts of the world and among the young in particular, this has transformed societal and marketing interactions.

\section{Quaternary Total Corporate Communications. What are they? What of them ?}

To reiterate, whilst the literature on the internet and the internet of things has burgeoned to date there appears to be of paucity of insights apropos the internet of things/the internet as discussed from a total corporate communications perspective.

As such, an additional dimension of total corporate communications should be considered namely that of quaternary total corporate communications which encompasses the communication dimension of both the internet of things and, more broadly, the communications effects and effects of the internet per se.

From our deliberations on the internet of things/the internet, we perceived the internet as a new dimension of the total corporate communications realm which, to mix our metaphors, can be compared to a communications cosmos. As such, because of its ability to communicate, evaluate and recommend organisations and their brands and 
because it provides assessments of corporate image and corporate reputation it may, perhaps, be considered a fourth dimension of total corporate communications that may be called quaternary total corporate communications.

Moreover, since the internet of total corporate communications transcends and impacts on the other three dimensions of total corporate communications it can be compared to a galaxy. As such Fig 3 below not only shows the four dimensions of total corporate corporate communications but shows the fourth dimension (quaternary corporate communications) overlapping with the others.

[Insert Figure 2: Internet of corporate communications: transcending primary, secondary and tertiary corporate communications here]

- internet of corporate communications: transcending primary level corporate communications

For some companies the internet is, of course, their primary modus operandi and as such their provision of internet services and support (including support apropos the IOT). Furthermore, for internal stakeholders, such as managers and employees, the nature, utilisation and management etc. of a company's internal email, intranet etc. systems can also be seen as a dimension of primary communications. In addition, chipembedded staff cards store personal information that helps firms differentiate internal employees from external stakeholders. Whilst staff cards are used to activate locked doors and machines such as printers and computers, they also record data that track of employees' activities and movement within the premises.

According to the precepts of total corporate communications, the activities, products and services and behaviours of organisations represent the primary level of total corporate communications (Balmer and Gray 1999).

- internet of corporate communications: transcending secondary level corporate communications]

An organisation's planned and coordinated corporate communication strategies and core messages aimed at internal stakeholders, customers and other key stakeholder 
groups utilising the internet (corporate websites, apps, advertising and electronic newsletters) can be considered a dimension of secondary corporate communications.

According to the precept of total corporate communications, the formal communications efforts aimed at key stakeholders represent the secondary level of total corporate communications (Balmer and Gry, 1999). Whilst traditionally mass media is employed to communicate standardised corporate message, now loT enabled apps often allow corporates to provide more tailored messages and information based on analysis of individual customers' usage behaviour and their indicated preference. For example, BBC news app provides users tailored news based on individuals' selection of newsworthiness and browsing behaviour. The messages are still very much controlled by the organisations; however the users now have the freedom to choose which ones they'd receive. Manufacturing suppliers also utilise the IoT to monitor their customers stocking.

- internet of corporate communications: transcending tertiary level corporate communications

The utilisation of the internet by internal and external stakeholders, competitors, interest groups, the media and others apropos word-of-mouse (word of mouth) commentary and automatically generate recommendations about an organisation represents another critically important total corporate communications dimension.

According to the precept of total corporate communications, the above third party narratives and dialogues about an organisation represent the tertiary level of total corporate communications (Balmer and Gray, 1999). However, whilst the loT now tracks users' browsing history and purchasing behaviour, a new recommendation system is now developed without the need of requiring further actions from customers to review or suggest. Instead by analysing and evaluating existing browsing history and purchasing behaviour (Choi, Lee, Han, Man and Chong, 2015), loT now provides recommendations to new customers by analysing previous customers behavioural data in relation to the same product/brand/corporate. For example, Amazon now recommends customers a list of products/brands/movies/music that others users have also bought based on their browsing and purchasing history to help customers identify competitive alternatives. 


\section{Impacts of quaternary total corporate communications}

Quandary communications gives individuals, groups, systems and machines beyond stakeholders' access to the internet, enabling them to exchange information about an organisation among themselves as well as providing feedback. In short quaternary communications is akin to a network and a network which operates on different internet platforms, connecting people, corporates and machines.

Secondly, quaternary communications further diffuse the controllable aspects of corporate communications and requires organisation to be far more astute in terms of the nature and impact of the IoTCC effects. Quaternary communications in effect is a constellation of corporate networks, enabled by loT platforms through connected actor bonds, resource ties and coordinated activities (e.g. Hakansson and Snehota 1995). Nevertheless, dissimilar to business networks that are developed and managed by senior managers for the business performance and competitive advantages, the loT network expands autonomously, through multiple connections among people, corporates, and machines, leading to a new ubiquitous computing and communication era (Tan and Wang, 2010).

Thirdly, quaternary communications also have an upside for organisations in that it empowers companies in terms of the availability of big data through connected cloud space (Gubbi, Buyya, Marusic, Palaniswami, 2013). The latter, collected and made available through the IoT, provides valuable resources for organisations to share their understanding of the markets and consumers with and amongst each other.

\section{The dark side of IOT and the Internet of Total Corporate Communications}

Although loT empowers humans by brining extra convenience to consumers as well as providing valuable marketing information to business, one cannot deny that the self-expanding information universe is not necessarily a galaxy, wherein all information are exchanged freely amongst humans and machines. Whilst the internet can be controlled through the use of fire walls or utilised by governments in order to "regular" communication (MacKinnon, 2010), this reflects the dark side of the phenomenon. Firms and marketers are therefore advised to be cautious when interpreting and analysing loT data for consumer insights. In fact, attention should be made to gain a full understanding 
in terms of how the data is collected to ensure validity and reliability, critical to reach sound and convincing conclusions.

\section{Marketing Management Implications}

Whilst the loT provides a new platform that expands the original corporate communications framework of Balmer and Gray, (1999), marketers are recommended to take advantages of this new platform by taking initiative to better understand how various data could be collected and collect them from the quaternary communications galaxy in order to obtain valuable consumer insights.

For example, by incorporating augmented reality and GPS to connect to the realworld places, thus creating a unique user experience when catching virtual cartoonmonsters (West, 2016), the app “Pokemon Go” brings not only profits to Nintendo, but also great access to consumer insights. Whilst the game remembers and records actual behavioural data of million users around the world, such big data could be analysed to obtain valuable consumer insights about when consumers go out, where they go and how long they stay at each spot. Such locality data if analysed appropriately, will be of great interest to local businesses, high-street retailers as well as media purchasing agencies.

Businesses are also advised to consider how loT could be incorporated at a strategic level to enhance their total corporate communications with both internal and external stakeholders. Resourceful corporates are recommended to work on developing and advancing their own devices, apps, processes and/or systems utilising loT in order to better engage and serve existing and prospective customers.

However, the advantages offered by loT are not only reserved for the more resourceful, SMEs can also stay on top of the trend by keeping an eye on the latest development in the market and take initiatives to utilise such opportunities creatively. For instance, Nintendo allows users to nominate local business spots as special resource bases in the virtual game, hence drawing people to gather around the area in reality. SMEs such as estate agents, restaurants and local shops quick to respond to this free promotion opportunity by self-nominating as special resource bases are likely to draw more visits from customers who are into the game. 


\section{Reflections and limitations}

The Internet of things (IOT) has spread into various areas with rapid expansion and impact. Whilst this fourth generation of industrial revolutions challenges existing marketing practices, we therefore introduce the notion of the Internet of Total Corporate Communications (IoTCC), as the quaternary power that facilitates the corporate marketing internet revolution.

To address the pressing matter that many organisations suffer from coordinated and integrated communications at the corporate level, we illustrate how the loT could be employed to facilitate total corporate brand communications at primary, secondary, territory and quaternary levels with a conceptual framework.

At primary communication level, the loT implementation in forms of intranet and internal email systems facilitates communication with internal stakeholders, this, in part, reveals key dimensions of an organisation's corporate identity. At the secondary corporate communications level, the IOT is used as part of an organisation's (controlled) integrated corporate communications efforts to promote and project corporate identity to customers, employees and other stakeholder groups via corporate marketing channels. At the territory level, the loT is engaged by external stakeholders, and others, in providing narratives on the firm and, as such, these provide valuable platforms in evaluating an entities actual, espoused and conceived corporate identity along with its corporate reputation.

Specifically at the quaternary level, the loT gives all stakeholders access to the internet and beyond, enabling them to exchange information and feedback, akin to a galaxy which operates on different platforms, connecting people, corporates and machines. This framework provides corporate marketing managers a comprehensive perspective to evaluate and plan strategically how loT could be implemented to better communicate its corporate identity, image and reputation, as well as serving and predicting customers' unmet needs. Nevertheless, when interpreting information exchanged on IOT, caution should be exercised regarding data reliability, validity and limitations.

Following our discussion, future studies interested in IoTCC are encouraged to further explore: 
- How loTCC empowers different stakeholders, impacting on the corporate identity, image and reputation?

- To what extent does IoTCC facilitates bi-lateral company - stakeholder relationships in relation to corporate reputation enhancement?

- IoT as a sector, its boundary vs. organisation and impact on corporate communications (e.g. China - state controlled loT environment, google controlled IoT environment).

- IOTCC consumers - how does their behaviour differ from previous generations?

\section{References}

Atzori, L., lera, A., Morabito, G. (2010) The Internet of Things: A survey, Computer Networks, 54, 2787-2805, doi:10.1016/j.comnet.2010.05.010.

Balmer, J. M. T. and Gray, E. R. (1999)Corporate identity and corporate communications: creating a competitive advantage, Corporate Communications: An International Journal, 4 (4), 171 - 177, doi: http://dx.doi.org/10.1108/EUM0000000007299

Balmer, J.M.T and Greyser, S. A. (2006) Corporate marketing: Integrating corporate identity, corporate branding, corporate communications, corporate image and corporate reputation, European Journal of Marketing, 40, 730-741, doi: 10.1108/03090560610669964.

Balmer, J.M.T. (2011) Corporate heritage identities, corporate heritage brands and the multiple heritage identities of the British Monarchy, European Journal of Marketing. 45 (9/10), 1380-1398, doi: 10.1108/03090561111151817.

Choi, S., Lee. H. Han, Y., Man, K. and Chong, W. (2015) A Recommendation Model Using the Bandwagon Effect for E-Marketing Purposes in IoT, International Journal of Distributed Sensor Networks, 1-7, doi: 10.1155/2015/475163.

Chui, M., Löffler, M. and Roberts, R. (2010) The Internet of Things, McKinsey Quarterly, (2), 1-9, Retrieved from http://www.mckinsey.com/industries/high-tech/ourinsights/the-internet-of-things.

Gubbi, J., Buyya, R., Marusic, S. and Palaniswami, M. (2013) Internet of Things (IoT): A Vision, Architectural Element, and Future Directions, Future Generation Computer Systems, 29 (7), 1645-1660, http://dx.doi.org/10.1016/j.future.2013.01.010. 
Jones, R., Suoranta, M., \& Rowley, J. (2013). Strategic network marketing in technology SMEs. Journal of Marketing Management, 29 (5-6), 671-697, doi:10.1080/0267257X.2013.797920.

MacKinnon, R. (2010, October) Networked Authoritarianism in China and Beyond: Implications for global Internet freedom, paper presented at Liberation Technology in Authoritarian Regimes, Standford University. Retrieved from http://fsi-media.stanford.edu/evnts/6349/MacKinnon_Libtech.pdf

The Economist (2016a), Where the smart is. June 11. p. 65, Retrieved from http://www.economist.com/news/business/21700380-connected-homes-will-takelonger-materialise-expected-where-smart

Roberts, J. (2004) The Modern Firm, Oxford University Press, Oxford.

Schwab, K. (2015) The Fourth industrial Revolution, What It Means and How to Respond, Foreign Affairs, Retrieved from https://www.foreignaffairs.com/articles/2015-1212/fourth-industrial-revolution.

Tan, L. and Wang, N. (2010) Future internet: The Internet of Things, 3rd International Conference on Advanced Computer Theory and Engineering (ICACTE) Chengdu, China, 5, 5376, doi: 10.1109/ICACTE.2010.5579543.

West, D. (2016) “How Pokemon Go will change just about everything”, Newsweek, Retrieved from http://europe.newsweek.com/how-pokemon-go-will-change-justabout-everything-485142.

Yadav, M.S., Prabhu, J.C, \& Chandy, R.K. (2007). Managing the future: CEO attention and innovation outcomes, Journal of Marketing, 71 (4), 84-101, doi: http://dx.doi.org/10.1509/jmkg.71.4.84

Yu, X., Nguyen, B., \& Chen, Y. (2015). Internet of Things capability and alliance: entrepreneurship orientation, market orientation, and product and process innovation, Internet Research, 26 (2), 402-434, http://dx.doi.org/10.1108/IntR-102014-0265 
Figure 2: The total corporate communications effect of the internet of things

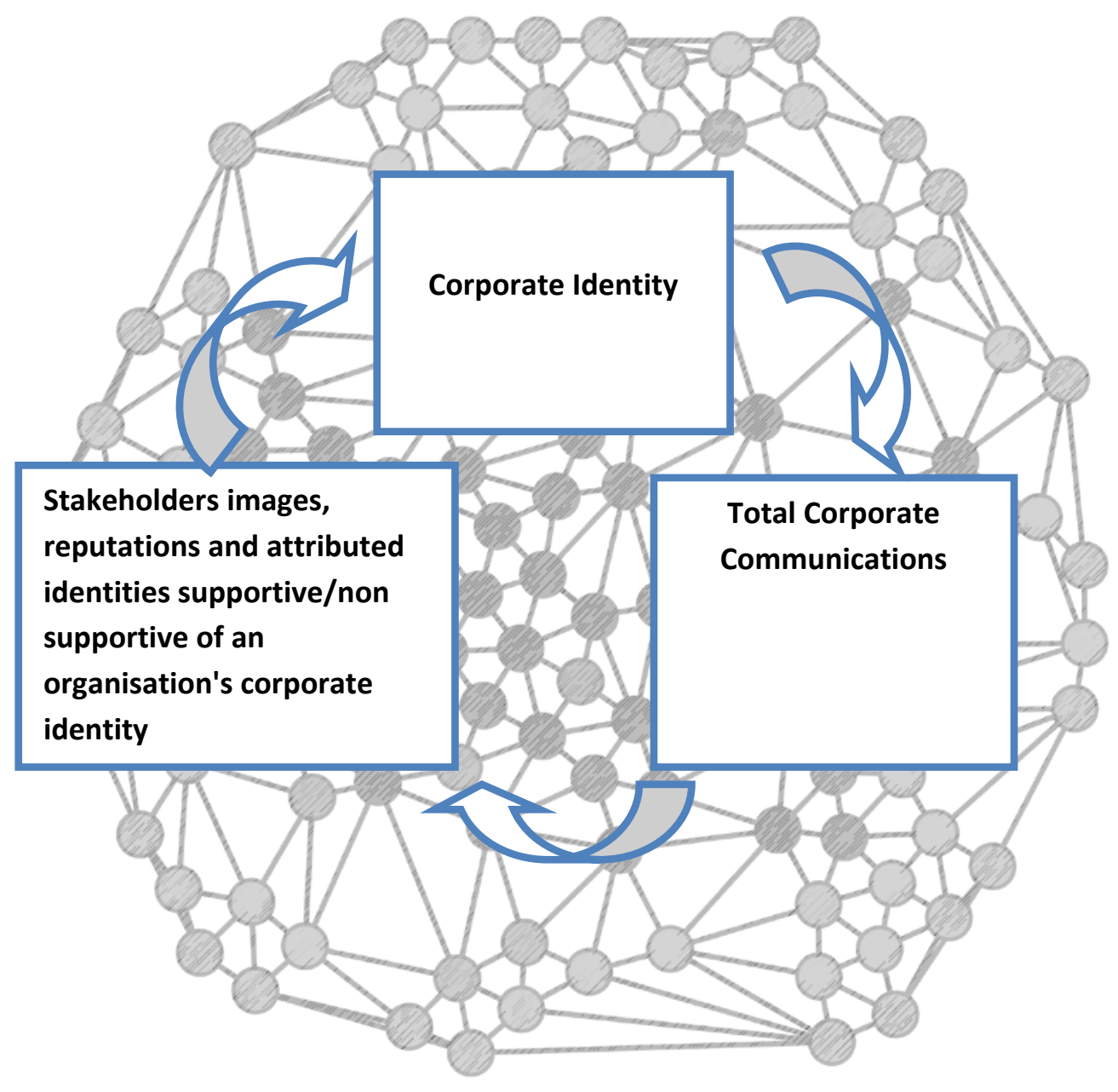


Figure 2: Internet of corporate communications: transcending primary, secondary and tertiary corporate communications

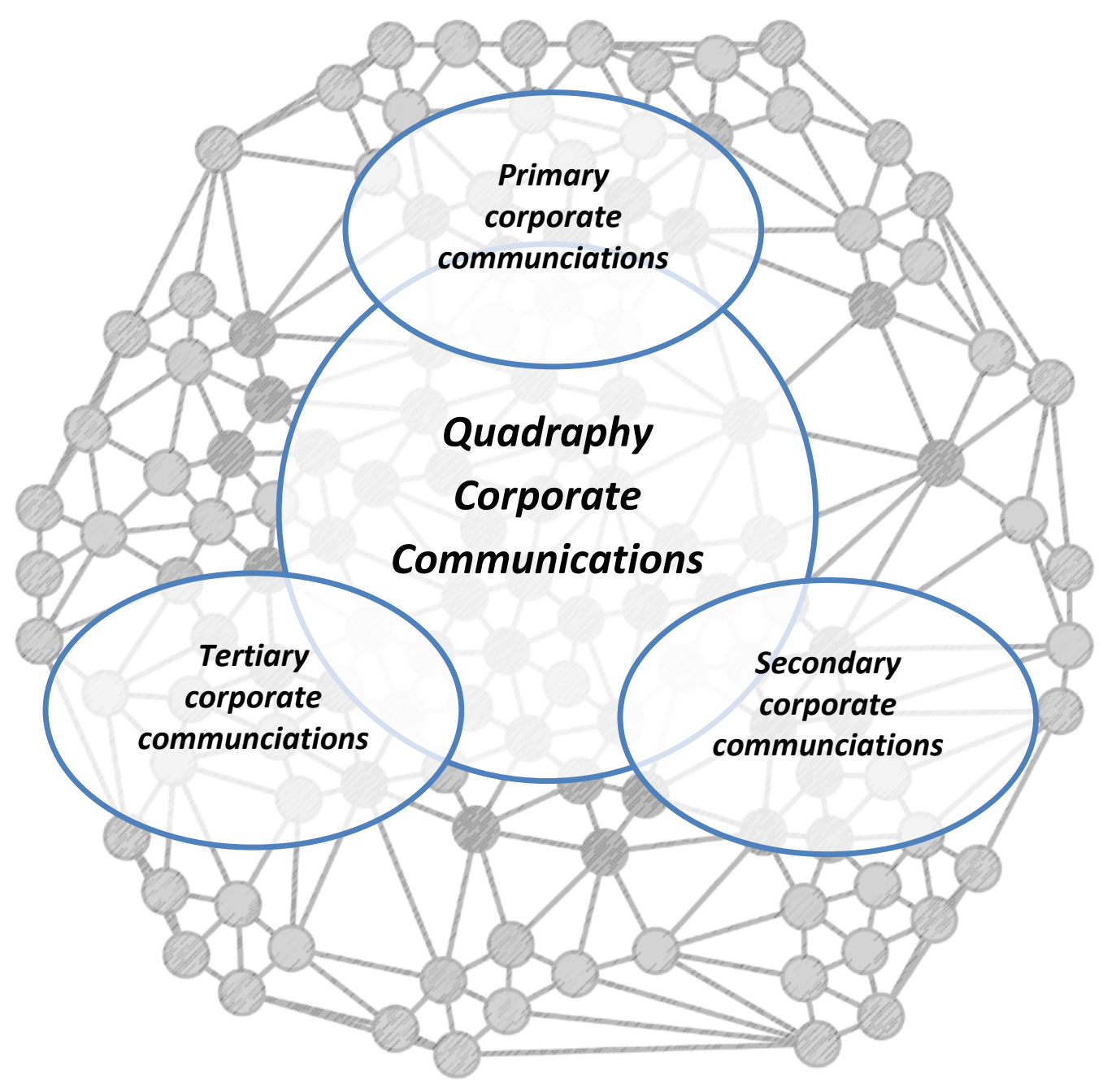




\section{ABOUT THE AUTHORS}

\section{John M.T. Balmer,}

is Professor of Corporate Marketing at Brunel University Business School London; quondam Professor of Corporate Brand/Identity Management at Bradford University School of Management and Director of the Marketing and Corporate Brand Research Group at Brunel University. Took his PhD at Strathclyde University in 2006 and within 3 years was elected to a personal (full) chair as Professor of Corporate Identity at Bradford University School of Management. Subsequently, he was conferred the title of Professor of Corporate Brand/Identity Management at the same institution in recognition of his pioneering scholarship in these fields. In 2007 he was appointed to a personal chair at Brunel University London where and was conferred the title Professor of Corporate Marketing. All three professorial appointments are understood to be the first of their kind. Recognised for his scholarship on corporate identity, he is credited with writing the first articles on corporate brands (1995) and corporate marketing (1998) and codeveloped the corporate heritage notion (2006). He is the Chairman of the Board of Senior Consultant Editors of the Journal of Brand Management; sits on the senior advisory board of the Journal of Product and Brand Management and was a long-time member of the editorial board of the Journal of Marketing Management. He has edited/co-edited well over 20 special editions of academic journals. His articles have been published in California Management Review, British Journal of Management, European Journal of Marketing, Journal of Business Research, Long Range Planning, Industrial Marketing Management, International Studies of Management and Organizations, Journal of Brand Management, Journal of General Management among other journals. In 1994 he established the International Corporate Identity Group (ICIG). Launched in the House of Lords (Palace of Westminster, London) he is the Chairman and Conference Organiser of the ICIG: symposia have been held in Denmark, Malaysia, South African, Spain, Switzerland as well as at the Universities of Oxford, Strathclyde, Brunel, Essex, and at the Queen Elizabeth II Conference Centre in London. He established the International Corporate Heritage Symposium in 2011 and is its Chairman and Conference Organiser.

\section{Dorothy Ai-wan Yen,}

is a Senior Lecturer in Marketing at Brunel University London. She graduated from the University of Leeds with a PhD in Marketing in 2008. Her research focuses mainly on the examination of cross-cultural interactions at both b2b and b2c levels. She specializes in the business relationships between Anglo-Saxon suppliers and Chinese buyers and has a particular research interest in the Chinese relational notion of guanxi. Her works have been published in journals such as Industrial Marketing Management, Journal of Business Research, Journal of Marketing Management, Journal of General Management, Total Quality Management, The Marketing Review and Studies in Higher Education. Since completing her PhD, Dorothy has gained extensive academic experience from lecturing in several UK universities and she is currently an external examiner in Marketing at Middlesex University. She has reviewed papers for a number of academic journals such as Industrial Marketing Management and Journal of Business Research. Prior to her academic career, she worked for several years in Advertising and Market research both in Taiwan and in the UK. 